Ramabaja Q., Rashiti N., Shkodra M., Ramadani L. The impact of some morphological and motor characteristics in short distance $\begin{array}{lllllll}\text { running. Journal of Education, Health and Sport. 2021;11(6):109-119. } & \text { eISSN 2391-8306. DOI }\end{array}$ http://dx.doi.org/10.12775/JEHS.2021.11.06.012

https://apcz.umk.pl/czasopisma/index.php/JEHS/article/view/JEHS.2021.11.06.012

https://zenodo.org/record/5016832

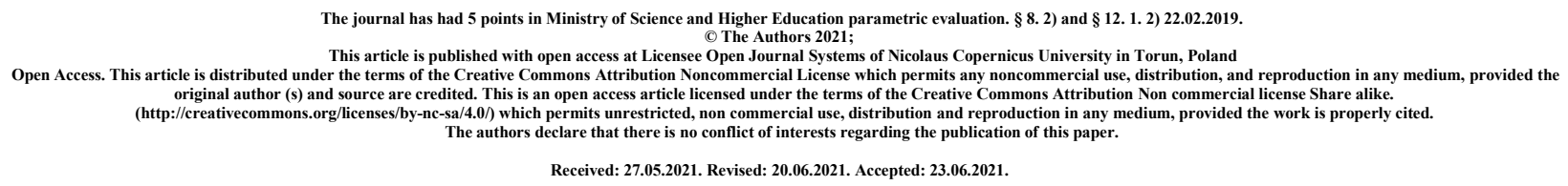

\title{
THE IMPACT OF SOME MORPHOLOGICAL AND MOTOR CHARACTERISTICS IN SHORT DISTANCE RUNNING
}

\author{
Ramabaja Q. ${ }^{1}$, Rashiti N. ${ }^{1}$, Shkodra M. ${ }^{2}$, Ramadani L. ${ }^{3}$ \\ ${ }^{1}$ University of Pristina, Faculty of Physical Education and Sport, Pristina, Kosovo \\ ${ }^{2}$ College AAB, Pristina, Kosovo \\ ${ }^{3}$ Faculty of Physical Education, Sports and Health, Skopje, Makedonia
}

\begin{abstract}
The knowledge of morphological development and their impact on motor skills in short-distance athletes should be one of the main concerns of athletics coaches, because any scientific research in the field of physical culture and sports is about proving the development and evaluation of anthropological characteristics which are responsible for achieving success in athletics. The purpose of this paper is to confirm the impact of some anthropometric characteristics in the execution of running speeds on short distances, specifically in running at 100, 200 and 400 meters to students aged $18 \pm 6$ years of the Faculty of Physical Education and Sports in Prishtina. The sample of this research has included a total of 60 students aged 18 years of the Faculty of Physical Education and Sports in Prishtina. The measurements were executed during September in the hall of the Faculty, while the 100, 200, and 400 meter runs in the stadium "Fadil Vokrri" Prishtina. The only condition that was used during the determination of the sample was: that the students are involved in regular physical education classes (and on the day of the measurement be healthy, without the flu, cold or other symptoms). The variables which are applied in this research have been 8 anthropometric variables and 3 motor-specific variables. The results obtained after their processing indicate that the impact of anthropometric variables is higher in running at 100, 200 and 400 meters. Short distance running and long distance running reduces the impact of anthropometric parameters whereas the influence of metabolic factors of energy production is increased. These results were also confirmed using regression analysis, so that
\end{abstract}


groups of predictors of anthropometric characteristics, specific motor skills that statistically significantly influenced each variable of individual criteria. The world records below the 10second limit, in the $100 \mathrm{~m}$, near the 9-meter limit, show not only the high level of sports, but also the strong impact on the growth, especially of strength indicators, speed-strength, explosive force, as main and applied motor skills in sports and athlete's everyday life.

Key words: anthropometry, criterion variables, regression, student.

\section{INTRODUCTION}

Athletic operates on the basis of a particular system of knowledge that has in its content the theoretical and methodological foundations of sport training [1]. Athletics affects the strengthening of health, during active participation with walking, walking-running and running, in different cross country of individual and massive character, which develop regularly. Running is the most universal mean of comprehensive preparation of the athlete, but it also occupies a very important place in the training of other types of sports. During running, the body appears more demands on the work of the muscular system and cardiovascular and respiratory activity. It is an important mean for maintaining and strengthening health. Athletic running, as a set of physical movements of a cyclic character, realizes displacement in space and time through steps with the lower limbs (legs) at a higher speed than in race walking. Running speeds, as well as long jumps and triple jumps, are natural forms of movement performance in general, and athletics in particular. These types are one of the basic means of comprehensive preparation: physical, functional and psychological [2,3] This is the main reason why they are constantly evaluated, especially in the context of purposeful exercise for sports achievements. Climatic conditions play a role in running results. The wind, depending on which direction it blows, can affect the growth or deceleration of the athlete's speed. Although it applies to all competitors in a given place and moment, the problem is that the results of a wind-blown place may be different from the results of another event in the same discipline, so in running 100, 200 and 400 meters. [4,5] Atmospheric pressure or air pressure may be considered, but it has no effect because running is too short and the amount of oxygen for this distance is mostly concentrated in the muscles of the runners. An athlete may not have building muscles, but he is taller and has the largest step. In this context, statistical tests and interpretation of results in separate sub-headings have been performed.

\section{PURPOSE OF THE RESEARCH}

Like any research of a transversal character that aims to prove the relationships, impact, dependence between different anthropological characteristics, skills and conditions, even this research is based on proving the influence of one anthropological field with the other in order to increase the information in favor of identifying the factors that are of particular importance in increasing the motor skills of anaerobic character speed. [6-19]. 
The knowledge of morphological development and their impact on motor skills of athletes in short tracks should be one of the main concerns of athletics coaches, because any scientific research in the field of physical culture and sport is about proving the development and evaluation of anthropological characteristics which are responsible for achieving success in athletics.

The purpose of this paper is to confirm the impact of some anthropometric characteristics on the speed of execution of running on short tracks, specifically in running 100, 200 and 400 meters for 18-year-old students.

\section{VARIABLES SAMPLE}

\section{Anthropometric variables}

The following morphological parameters have been applied for the identification of morphological variables: Body Height (BH), Leg Length (LL), Body Weight (BW), Chest Circumference (ChC), Elbow Diameter (ED), Knee Diameter (KD), Subcutaneous Adipose Tissue of the arm (SATAr) Subcutaneous Adipose Tissue of the abdomen (SATAb).

\section{Specific-motor variables}

The following parameters have been applied for the identification of specific motor skills: Running 100 meters from low start (MV100MU), Running 200 meters from low start (MV200MU), Running 400 meters from low start (MV400MU).

\section{METHODS FOR PROCESSING RESULTS}

Based on the goal and the hypotheses presented, the methods of processing the results have been applied, which enable the provision of sufficient information to achieve the goal.

For both groups of the variable system, the basic statistical and distribution parameters for each variable are calculated, as well as the asymmetry and normal distribution measures.

Minimum and Maximum Values (R.min - R.max), Arithmetic Mean (Ma), Standard Deviation (Std. Dev), Asymmetry Parameters (SKEW and KURT), Interrelationships between variables in the manifest space, as well as correlations between the system of variables.

To determine the relationship between predictive variables (anthropometric characteristics) and criterion variables (Results in short running), Regressive Analysis was applied in the manifest space.

\section{INTERPRETATION OF RESULTS AND DISCUSSION DESCRIPTIVE ANALYSIS OF ANTHROPOMETRIC AND MOTOR SPECIFIC VARIABLES}

In Table 1 descriptive analysis of anthropometric and motor specific variables is presented to the 18-year-old students of the Faculty of Physical Education and Sports.

The sample included a group of 60 male students, where the arithmetic mean values, minimum score, maximum score, standard deviation, distribution or asymmetry parameters (Skewness - tilt, 
asymmetry) and the degree of extension of the curvature peak of the distribution of results (Kurtosis - convexity).

Table 1. Basic statistical parameters of anthropometric and motor specific variables in students of the Faculty of Physical Education and Sports.

\begin{tabular}{|l|r|r|r|r|r|r|r|}
\hline Tab.1 & N & Minimum & \multicolumn{1}{c|}{ Maximum } & \multicolumn{1}{c|}{ Mean } & Std. Deviation & Skewness & Kurtosis \\
\hline ALART & 60 & 156.70 & 184.60 & 172.6550 & 5.61772 & -.151 & .360 \\
\hline AGJKË & 60 & 85.80 & 105.40 & 96.7195 & 4.73850 & -.283 & -.617 \\
\hline APESH & 60 & 49.40 & 93.50 & 64.0083 & 7.96312 & 1.073 & 2.549 \\
\hline APGJO & 60 & 76.90 & 100.40 & 85.6150 & 6.03748 & .824 & -.276 \\
\hline ADBRY & 60 & 6.00 & 9.90 & 7.4550 & .74480 & 1.062 & 1.651 \\
\hline ADGJU & 60 & 8.70 & 12.60 & 10.0683 & .70579 & .824 & 2.224 \\
\hline AIDHK & 60 & 3.80 & 19.60 & 7.2183 & 3.06448 & 1.842 & 4.167 \\
\hline AIDHB & 60 & 4.80 & 24.20 & 10.0550 & 4.78300 & 1.463 & 1.588 \\
\hline MV100MU & 60 & 12.14 & 14.21 & 13.1297 & .48962 & -.044 & -.818 \\
\hline MV200MU & 60 & 25.08 & 39.77 & 29.7018 & 3.13092 & 1.214 & 1.665 \\
\hline MV400MU & 60 & 66.95 & 98.35 & 82.3832 & 7.62531 & .262 & -.785 \\
\hline
\end{tabular}

The arithmetic mean of the anthropometric variable, Body height $(\mathrm{BH})$ is $172.65 \mathrm{~cm}$. Minimum results $(156.70 \mathrm{~cm})$ and the maximum $(184.60 \mathrm{~cm})$ of the variable. Body height $(\mathrm{BH})$ indicates a marked difference between students of this age in this anthropometric parameter. Although the results indicate that there is a marked difference between the maximum and minimum result, it can be seen that the flexibility and convexity of the obtained distribution (Skewness and Kurtosis) do not indicate a pronounced asymmetry...

Histogram 1, 2 and 3 of the specific motor variable, running 100, 200 and 400 meters from low start (MV100MU) to 18-year-old students.
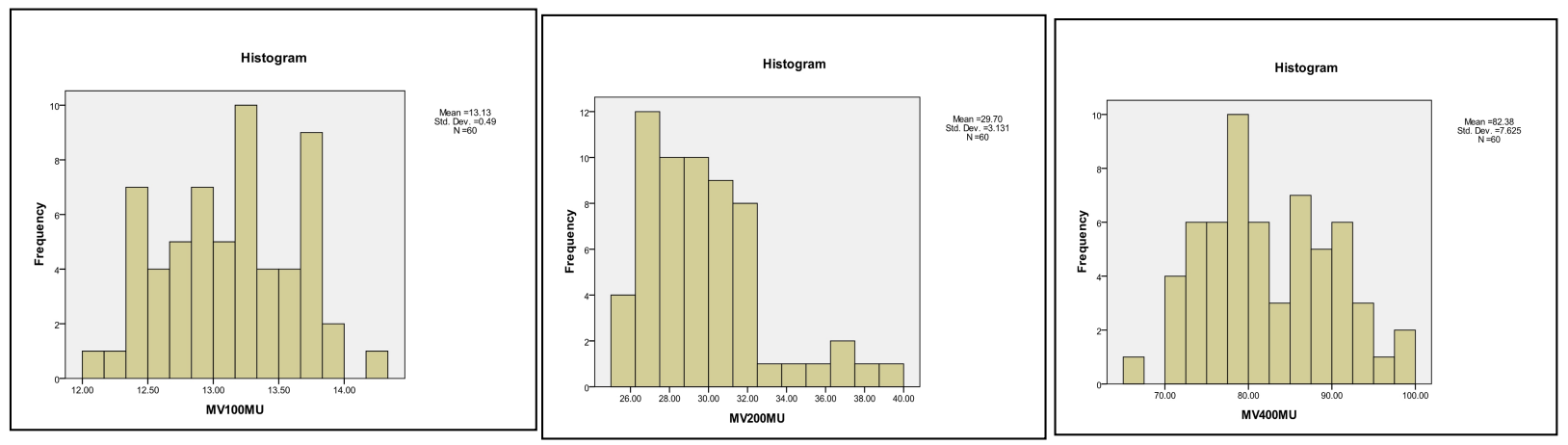

The arithmetic mean of the specific motor variable, Running 100 meters from low start (MV100MU) is $13.12 \mathrm{sec}$. Minimum result $(12.14 \mathrm{sec})$ and the maximum $(14.21 \mathrm{sec})$ of the variable Running 100 meters from low start indicates a significant difference between students of this age in this specific motor parameter. Although the results show that there is a marked difference between the maximum and the minimum result, it can be seen that the flexibility and convexity of the obtained distribution (Skewness and Kurtosis) do not indicate a pronounced asymmetry. 
The arithmetic mean of the specific motor variable, Running 200 meters from low start (MV200MU) is $29.70 \mathrm{sec}$. Minimum result $(25.08 \mathrm{sec})$ and the maximum $(39.77 \mathrm{sec})$ of the variable Running 200 meters from low start indicates a significant difference between students of this age in this specific motor parameter. Although the results show that there is a marked difference between the maximum and the minimum result, it can be seen that the flexibility and convexity of the obtained distribution (Skewness and Kurtosis) do not indicate a pronounced asymmetry.

The arithmetic mean of the specific motor variable, Running 400 meters from low start (MV400MU) is $82.38 \mathrm{sec}$. Minimum result $(66.95 \mathrm{sec})$ and the maximum $(98.35 \mathrm{sec})$ of the variable Running 400 meters from low start indicates a significant difference between students of this age in this specific motor parameter. Although the results show that there is a marked difference between the maximum and the minimum result, it can be seen that the flexibility and convexity of the obtained distribution (Skewness and Kurtosis) do not indicate a pronounced asymmetry.

\section{Coefficients of correlations between specific motor variables}

The inter-correlation matrix of the anthropometric variables of 18-year-old students is presented in Table 2. The interpretation of simple linear correlation coefficients, as it is known for the most part, depends on the number of subjects tested, respectively more precise on the degree of freedom.

Table. 2 of the correlation of specific motor variables

\begin{tabular}{|l|r|r|r|}
\hline & MV100MU & MV200MU & MV400MU \\
\hline MV100MU & 1 & $.577^{* *}$ & $.265^{*}$ \\
\hline MV200MU & $.577^{* *}$ & 1 & $.295^{*}$ \\
\hline MV400MU & $.265^{*}$ & $.295^{*}$ & 1 \\
\hline
\end{tabular}

Running at 100 meters from low start (MV100MU) lies in significant statistical correlation with Running at 200 meters from low start (MV200MU) with correlation coefficient $r=0.577$ at probability level $\mathrm{p}<0.01$ and Running at 400 meters from low start (MV400MU) with correlation coefficient $r=0.265$ at probability level $p<0.05$. Running at 200 meters from low start (MV200MU) lies in significant statistical correlation with Running at 100 meters from low start (MV100MU) with correlation coefficient $r=0.577$ at probability level $p<0.01$ and Running at 400 meters from low start (MV400MU) with correlation coefficient $r=0.295$ at probability level $\mathrm{p}<0.05$. Running at 400 meters from low start (MV400MU) lies in significant statistical correlation with Running at 100 meters from low start (MV100MU) with correlation coefficient $r$ $=0.265$ at probability level $\mathrm{p}<0.05$ and Running at 200 meters from low start (MV200MU) with correlation coefficient $\mathrm{r}=0.295$ at probability level $\mathrm{p}<0.05$. 


\section{Regressive analysis of antropometric and specific motor parameters}

Through regressive analysis in students, the value of the correlation between the group of independent predictor variables (anthropometric variables) and the dependent criterion variable Running at 100 meters from low start (MV100MU) has been proven.

Table 3. Regressive analysis - correlation and effect of anthropometric parameters (as predictor variables) on the criterion variable - Running 100 meters from low start

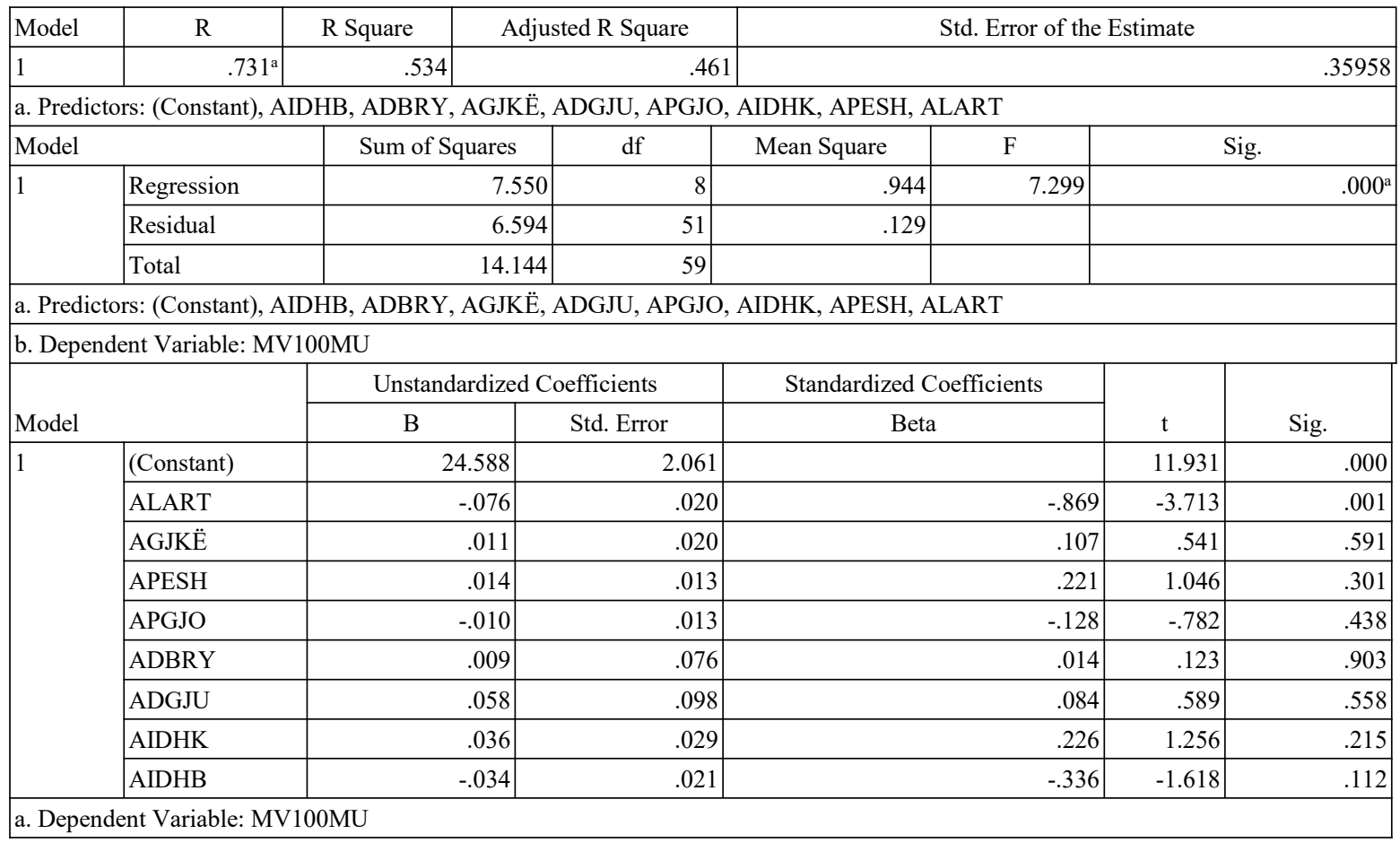

The correlation of the entire system of independent predictor variables (anthropometric variables) and the dependent criterion variable - 100 meters running from low start (MV100MU) has been proven by multiple correlations. The multiple correlation coefficient has the value $\mathrm{R}=0.731$ which explains the common variability between the system of predictor variables and the criterion variable about $53 \%$ ( $\mathrm{R}$ Square $=0.534)$.

Distribution (F) is obtained as the quotient distribution of the two variances, and it is always necessary in these cases to determine the two degrees of freedom. The first degree of freedom is equal to the number of predictor variables $(\mathrm{df}=\mathrm{n})$ in the concrete case, while $(\mathrm{df}=8)$ the second is performed so that the number of subjects decreases by the number of predicator variables minus $1(\mathrm{df}=\mathrm{N}-\mathrm{n}-1)$ in the concrete case, whereas $(\mathrm{df}=60-8-1=51)$.

We can emphasize that the test (F-test) is more valuable if the multiple correlation is greater, in the concrete case of this paper is significant ( $\mathrm{Sig}=0.00)$, because the value of the F-test is $=$ 7.299 .

In this research after a significant multiple correlation has been obtained $(\mathrm{R})$ it is necessary to look for which coefficient in the beta column (Beta) that shows the impact of each predictor 
(independent) variable on the dependent or criterion variable, Running 100 meters from the low start (MV100MU) table 3.

The results obtained from regression analysis indicate that in the dependent variable or Running 100 meters from low start (MV100MU) the anthropometric variable Body height (BH) has an effect, Beta $=-.869$ which is proven by the probability scale, Sig $=0.001$. No other applied anthropometric variable has a significant statistical impact on the execution of the criterion variable; 100 meters running from low start (MV100MU).

Through regressive analysis in students, the value of the relationship between the group of independent predictor variables (anthropometric variables) and the dependent criterion variable Running 200 meters from low start (MV200MU) was confirmed.

Table 4. Regressive analysis - correlation and impact of anthropometric parameters (as predictor variables) on the criterion variable - Running 200 meters from low start.

\begin{tabular}{|l|r|r|r|r|}
\hline Model & \multicolumn{1}{|c|}{ R } & R Square & Adjusted R Square & Std. Error of the Estimate \\
\hline 1 & $.565^{\mathrm{a}}$ & .320 & .213 & 2.77782 \\
\hline \multicolumn{2}{|l|}{ a. Predictors: (Constant), AIDHB, ADBRY, AGJKË, ADGJU, APGJO, AIDHK, APESH, ALART } \\
\hline
\end{tabular}

\begin{tabular}{|l|l|r|r|r|r|r|}
\hline \multicolumn{1}{|l|}{ Model } & Sum of Squares & df & Mean Square & \multicolumn{1}{c|}{ F } & Sig. \\
\hline \multirow{3}{*}{1} & Regression & 184.829 & 8 & 23.104 & 2.994 & $.008^{\mathrm{a}}$ \\
\cline { 2 - 7 } & Residual & 393.529 & 51 & 7.716 & & \\
\cline { 2 - 6 } & Total & 578.358 & 59 & & & \\
\hline
\end{tabular}

\begin{tabular}{|c|c|c|c|c|c|c|}
\hline \multirow{2}{*}{\multicolumn{2}{|c|}{ Model }} & \multicolumn{2}{|c|}{ Unstandardized Coefficients } & \multirow{2}{*}{$\begin{array}{c}\text { Standardized Coefficients } \\
\text { Beta }\end{array}$} & \multirow[b]{2}{*}{$\mathrm{t}$} & \multirow[b]{2}{*}{ Sig. } \\
\hline & & $\mathrm{B}$ & Std. Error & & & \\
\hline \multirow{9}{*}{1} & (Constant) & 67.084 & 15.920 & & 4.214 & .000 \\
\hline & ALART & -.363 & .158 & -.652 & -2.305 & .025 \\
\hline & AGJKË & .107 & .157 & .162 & .681 & .499 \\
\hline & APESH & .051 & .101 & .131 & .512 & .611 \\
\hline & APGJO & .106 & .102 & .204 & 1.034 & .306 \\
\hline & ADBRY & -.463 & .586 & -.110 & -.790 & .433 \\
\hline & ADGJU & .661 & .760 & .149 & .870 & .389 \\
\hline & AIDHK & .453 & .222 & .443 & 2.042 & .046 \\
\hline & AIDHB & -.381 & .164 & -.582 & -2.321 & .024 \\
\hline
\end{tabular}

The correlation of the entire system of independent predictor variables (anthropometric variables) and the criterion dependent variable - 200 meters run from low start (MV200MU) has been proven by multiple correlations. The multiple correlation coefficient has the value $\mathrm{R}=0.565$ which explains the common variability between the system of predictor variables and the criterion variable about $32 \%(\mathrm{R}$ Square $=0.320)$. Distribution $(\mathrm{F})$ is obtained as the quotient distribution of the two variances, and it is always necessary in these cases to determine the two degrees of freedom. The first degree of freedom is equal to the number of predictor variables ( $\mathrm{df}$ $=\mathrm{n})$ in the concrete case whereas $(\mathrm{df}=8)$ the second is performed so that the number of subjects 
decreased by the number of predictor variables minus $1(\mathrm{df}=\mathrm{N}-\mathrm{n}-1)$ in the concrete case whereas $(\mathrm{df}=60-8-1=51)$. We can emphasize that the test (F-test) is more valuable if the multiple correlation is greater, in the concrete case of this paper is significant (Sig $=0.008$ ), because the value of the F-test is $=2.994$. In this research after a significant multiple correlation has been obtained (R) it is necessary to look for which coefficient in the beta column (Beta) that indicates the effect of each predictor (independent) variable on the dependent or criterion variable, Running 100 meters from the low start (MV200MU) table 4. The results obtained from regressive analysis indicate that in the dependent variable or Running 100 meters from low start (MV200MU) the anthropometric variable Body height $(\mathrm{BH})$ has an effect, Beta $=-.652$ which is proven by the degree of probability, Sig $=0.025$. No other applied anthropometric variable has a significant statistical effect on the execution of the criterion variable; 100 meters running from low start (MV100MU).

Through regressive analysis in students, the value of the relationship between the group of independent predictor variables (anthropometric variables) and the dependent criterion variable Running 400 meters from low start (MV400MU) was confirmed.

Table 5. Regressive analysis - correlation and impact of anthropometric parameters (as predictor variables) in the criterion variable - Running 400 meters from low start

\begin{tabular}{|l|r|r|r|r|}
\hline Model & R & R Square & Adjusted R Square & Std. Error of the Estimate \\
\hline 1 & $.325^{\mathrm{a}}$ & .106 & -.035 & 7.75647 \\
\hline \multicolumn{2}{l|}{ a. Predictors: (Constant), AIDHB, ADBRY, AGJKË, ADGJU, APGJO, AIDHK, APESH, ALART } \\
\hline
\end{tabular}

\begin{tabular}{|c|c|c|c|c|c|c|}
\hline \multicolumn{2}{|c|}{ Model } & Sum of Squares & $\mathrm{df}$ & Mean Square & $\mathrm{F}$ & Sig. \\
\hline \multirow[t]{3}{*}{1} & Regression & 362.269 & 8 & 45.284 & .753 & $.645^{\mathrm{a}}$ \\
\hline & Residual & 3068.307 & 51 & 60.163 & & \\
\hline & Total & 3430.577 & 59 & & & \\
\hline \multicolumn{7}{|c|}{ a. Predictors: (Constant), AIDHB, ADBRY, AGJKË, ADGJU, APGJO, AIDHK, APESH, ALART } \\
\hline \multicolumn{7}{|c|}{ b. Dependent Variable: MV400MU } \\
\hline
\end{tabular}

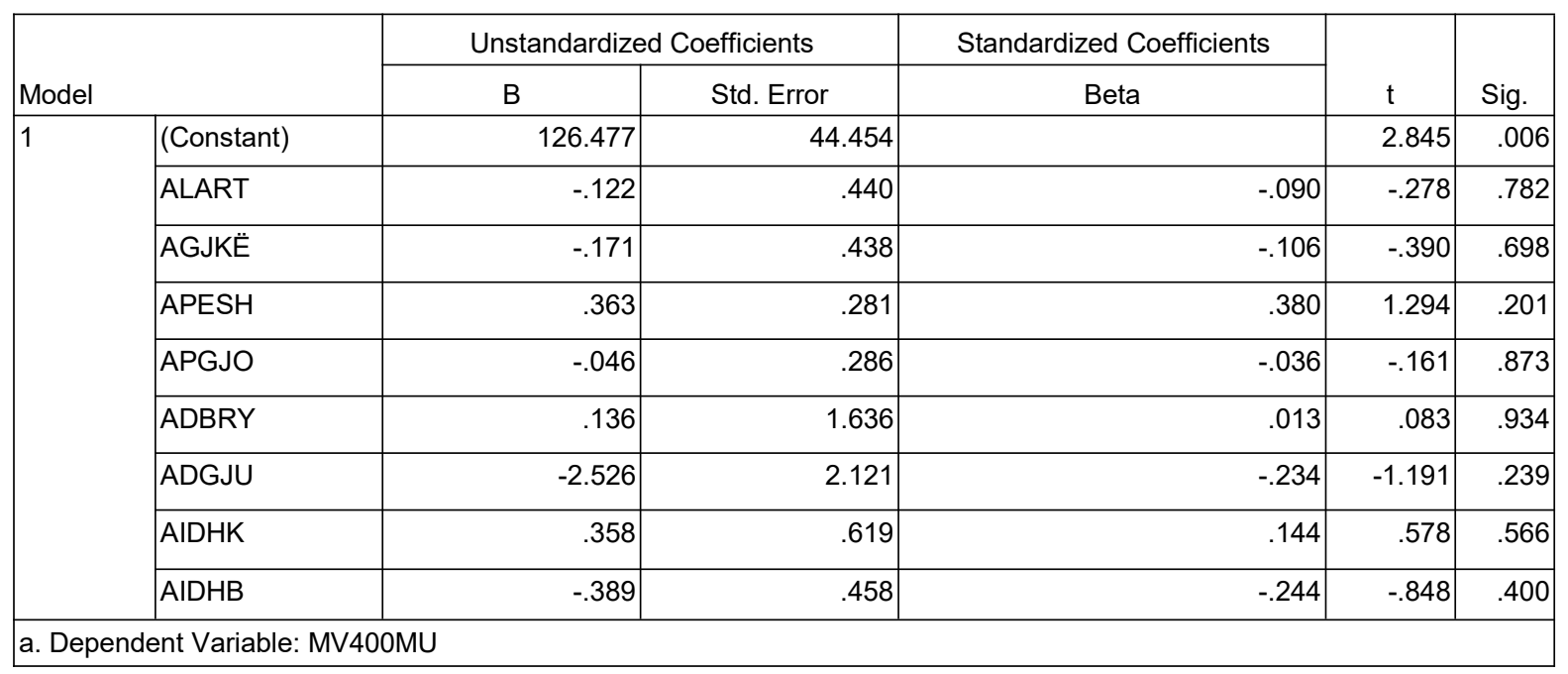

The connectivity of the entire system of independent predictor variables (anthropometric variables) and the dependent criterion variable - $400 \mathrm{~m}$ run from low start (MV400MU) has been proven by multiple correlations. The multiple correlation coefficient has the value $\mathrm{R}=0.325$ 
which explains the common variability between the system of predictor variables and the criterion variable about $10 \%(\mathrm{R}$ Square $=0.106)$.

Distribution (F) is obtained as the quotient distribution of the two variances, and it is always necessary in these cases to determine the two degrees of freedom. The first degree of freedom is equal to the number of predictor variables $(\mathrm{df}=\mathrm{n})$ in the concrete case whereas $(\mathrm{df}=8)$ the second is performed so that the number of subjects decreased by the number of predictor variables minus $1(\mathrm{df}=\mathrm{N}-\mathrm{n}-1)$ in the concrete case whereas $(\mathrm{df}=60-8-1=51)$.

We can emphasize that the test (F-test) is more valuable if the multiple correlation is greater, in the concrete case of this paper is significant ( $\mathrm{Sig}=0.645)$, because the value of the F-test is $=$ 0.753 .

No significant multiple correlation $(\mathrm{R})$ was obtained in this research and it is not necessary to require any coefficient of the beta column (Beta) indicating the effect of each predictor (independent) variable on the dependent or criterion variable, table 5.

The results obtained from regression analysis indicate that in the variable $400 \mathrm{~m}$ running from low start (MV400MU) does not affect any anthropometric variables applied.

\section{CONCLUSION}

It is known that the sports training system in athletics, respectively short-distance running consists of the training or preparation system, competition system and complementary factor system. The overall system of preparation of athletes is oriented towards the development and maintenance of general skills, qualities and knowledge on which success depends on the conditions of competitions. The athletic training process has many tasks which are solved through physical preparation, technical preparation, tactical preparation, psychological preparation and theoretical preparation. The purpose of this research is also based on these facts, which aims to prove the influence of some anthropometric characteristics on short-distance running. So, the purpose of this paper is presented based on these presented facts about the influence of morphological factors on short-distance running,.

In this paper (research) the population from which the sample was selected for research on this paper is defined as the population of students (male) of late adolescence.

The sample of this research has included a total of 60 students aged $18 \pm 6$ years of the Faculty of Physical Education and Sports in Prishtina.

For both groups of the variable systems, the basic statistical and distribution parameters for each variable were calculated, as well as the asymmetry and normal distribution measures, the correlation ratio, and regression analysis.

The results obtained from the collection of information as well as their processing show that:

a) some of the anthropometric characteristics have had pronounced asymmetry indicating that the sample has been heterogeneous in conditions of morphological development.

b) some of the specific-motor speed skills have had pronounced asymmetry indicating that the sample has been heterogeneous with different results.

c) anthropometric characteristics are grouped according to anthropometric factors which means that anthropometric characteristics of length are grouped as longitudinal factors, 
d) anthropometric characteristics of weight and perimeter are grouped as a factor of body mass and volume.

e) anthropometric characteristics of the subcutaneous adipose tissue of the arm and abdomen are grouped as a factor of subcutaneous fat mass.

f) the results obtained from regression analysis indicate that in the dependent variable or Running 100 meters from low start (MV100MU) the anthropometric variable Body height $(\mathrm{BH})$ has an effect, Beta $=-.869$ which is confirmed by the degree of probability, $\mathrm{Sig}=0.001$. No other applied anthropometric variables have a significant statistical effect on the execution of the criterion variable; 100 meters running from low start (MV100MU).

g) The results obtained from regressive analysis indicate that in the dependent variable or Running 100 meters from low start (MV200MU) the anthropometric variable Body height $(\mathrm{BH})$ has an effect, Beta $=-.652$ which is confirmed by the degree of probability, $\mathrm{Sig}=0.025$. No other applied anthropometric variables have a significant statistical effect on the execution of the criterion variable; 100 meters running from low start (MV200MU).

h) the results obtained from regressive analysis indicate that in the variable $400 \mathrm{~m}$ running from low start (MV400MU) it does not affect any anthropometric variables applied.

We can conclude that running on short tracks 400 meters, running on middle distances and long distances the effect of anthropometric parameters is decreased and the influence of metabolic factors of energy production is increased.

\section{REFERENCES}

[1] Rashiti N., Meta A ., "Studime Sportive" , "Funkcioni i aparatit vestibular në veprimtarit sportive", Vol. 5, No. 2. Pp. 7, 2002 Tiranë.

[2] Rashiti N., Elezi A., Maliqi A., "Националната спортна академия “, "Impact of some motor abilities on the manifestation of endurance with highschool students at the age 16 years", "В. Левски" broji 1 -10, 2010, Sofia

[3] Rashiti N., Nika F., Sylejmani B., "Montenegrin sport academy" "Prediktivna vrjednost baterije motoricnih testova na tercanje kratki i srednjih staze" Vol. 7, No. 3, pp.15,2011 , Montenegro.

[4] Rashiti V., Rashiti N,. "Journal of Sport Sciences “, "Atletska Ajrobia”, Zbornik Naucnih i Strucnih Radova” Tuzla, ISSN 1840-4790,Vol.5, pp.2-7, 2013 (10), 1019-1026

[5] Ramadani L., Heta G., Bekolli L., Rashiti N., Millaku A., "Journal of Education, Health and Sport", "The impact of short run distances to the final results of the decathlon at the 2019 Athletic World Championships", 2019;9(12):101-109. e ISSN 2391-8306. 2020

[6] Rashiti V., Ramadani L., Rashiti N., "St. Kliment Ohridski University", "The pole of the students educational background at elementary schools and their tesults", Faculty of Education - Bitola, Vol. 9, No. 1, God. 2020/2

[7] G Heta., L Bekolli., L Ramadani., Q Ramabaja., N Rashiti.," Difference between midfield and forward football players in active and passive Body Mass Index as well as in the aerobic capacity" Open Access ISSN 2391-8306 formerly ISSN: 1429-9623 / 2300$665 \mathrm{X}, 2020$ 
[8] Rashiti N., Myrtaj N., Xhemajli N., "Nauchni trudove na rusenskija universitet", Canon anthropometric relationship between the characteristics and specific motor abilities in football club in Gjilan, 2/ 2011 том 50, серия 8.2

[9] Rhea M. R., "Determining the magnitude of treatment effects in strength training research through the use of the effect size," Journal of Strength and Conditioning Research, vol. 18, no. 4, pp. 918-920, 2004. DOI: 10.1519/14403.1

[10] Rashiti N., Ajvazi V., Shkodra M., "Characteristicas anthopomertic and motor test for short running 100 meters (famales) ISSN 1311-3321, RUSE, Bugaria

[11] Rashiti N., Nika F., Bekolli L., Heta G., "Jurnal of physical activity and sports" "Difference Betwen finalists in antopometric parameters and 100 meters running of top athlete" vol. 2, no. 3, pp. 1-8, 2017. bot.2017.172689

[12] Spurrs, R.W., Murphy, A.J., \& Watsford, M.L. (2003). The effect of plyometric training on distance running performance. Eur J Appl Physiol, 89(1), pp.1-7

[13] Kaynak K., Eryilmaz S. K., Aydoğan S., Mihailov D., "The effects of 20-m repeated sprint training on aerobic capacity in college volleyball players," Biomedical Human Kinetics, vol. 9, no. 1, pp. 43-50, 2017. DOI: 10.1515/bhk-2017-0007

[14] Kotzamanidis C., "The effect of sprint training on running performance and vertical jumping in prea-dolescent boys," Journal of Human Movement Studies, vol. 44, no. 3, pp. 225-240, 2003.

[15] Mero A., Komi P. V., Gregor R. J., "Biomechanics of sprint running. A review," Sports Medicine, vol. 13, no. 6, pp. 376-392, 1992. DOI: 10.2165/00007256-19921306000002

[16] Wellenkotter J, Kernozek TW, Meardon SA, Suchomel TJ. The Effects of Running Cadence Manipulation on Plantar Loading in Healthy Runners. International Journal of Sports Medicine. 2014;35(9):1-6.

[17] Messier SP, Messier SP, Mihalko SL, Ip E, DeVita P, Cannon DW, et al. A 2-Year Prospective Cohort Study of Overuse Running Injuries: The Runners and Injury Longitudinal Study (TRAILS). The American Journal of Sports Medicine. 2018;46(9):2211-2221.

[18] Kessler DF. Running FASTER: Changing Running Technique to Reduce Stress Injuries. International Journal of Athletic Therapy and Training. 2020;25:49-53.

[19] Mokha M, Gatens D. Hip and Pelvis Biomechanics during Running as Risk Factors for Injury in Collegiate Runners: A Prospective Study. Journal of Exercise and Nutrition. 2018;1(4):1-6.

\section{Correspondence to:}

Rashiti Naser Ph.D.

University Prishtina

Faculty of Physical Education and Sport

Kosova

E-mail: labiont.dani@gmail.com 